\title{
Renin Angiotensin System Inhibition and Susceptibility and Outcomes from COVID-19: \\ A Systematic Review and Meta-analysis of 69,200 COVID-19 Patients
}

\author{
Yi Zhang, MD ${ }^{1 *}$; Shikai Yu, MD ${ }^{1 *}$; Yawei Xu, MD ${ }^{1}$; Bryan Williams, MD $^{2}$ \\ from
}

1. Shanghai Tenth People's Hospital, Tongji University School of Medicine,

Shanghai, China;

2. Institute of Cardiovascular Sciences, University College London, and National Institute for Health Research University College London Hospitals Biomedical Research Centre, London, UK.

* authors contributed equally to this manuscript.

Short title: ACEi/ARB use in COVID-19 pandemic

Word count: main text: 4352, Abstract: 310

Tables: 1, Figures: 4, Supplements: 1 File, PRISMA Checklist: 1

\section{Corresponding authors:}

Professor Yawei Xu

Cardiac center, Shanghai Tenth People's Hospital

Tongji University, 301 Middle Yanchang Road

Shanghai, China

yaweixu@tongji.edu.cn

Professor Bryan Williams

Chair of Medicine | University College London

Maple House $1^{\text {st }}$ Floor Suite A

149 Tottenham Court Road

London W1T 7DN

United Kingdom

bryan.williams@ucl.ac.uk 


\section{ABSTRACT}

Background: Early observational studies suggested that the use of the renin angiotensin system (RAS) inhibitors, specifically angiotensin converting enzyme inhibitors or angiotensin receptor blockers, may increase the risk of infection with SARS-CoV-2 and adversely affect the prognosis or survival of infected patients. To explore the impact of RAS inhibitor use on the risk of SARS-CoV-2 infection and the prognosis of SARS-CoV-2 infected patients, from all published studies.

Methods and Findings: A systematic review and meta-analysis of the use of RAS inhibitors in relation to infection with SARS-CoV-2 and/or the severity and mortality associated with COVID-19 was conducted. English language bibliographic databases PubMed, Web of Science, OVID Embase, Scopus, MedRxiv, BioRxiv, searched from Jan 1st, 2020 to July 20th, 2020. 58 observational studies (69,200 COVID-19 patients and 3,103,335 controls) were included. There was no difference in the susceptibility to SARS-CoV-2 infection between RAS inhibitor users and non-users (unadjusted OR 1.05, 95\% CI 0.90 to 1.21), (adjusted OR $0.93,95 \%$ CI 0.85 to 1.02 ), (adjusted HR $1.07,95 \%$ CI 0.87 to 1.31 ). There was no significant difference in the severe Covid-19 case rate between RAS inhibitor users and non-users (unadjusted OR $1.05,95 \%$ CI 0.81 to 1.36 ), (adjusted OR $0.76,95 \%$ CI 0.52 to 1.12), or in mortality due to COVID-19 between RAS inhibitor users and non-users (unadjusted OR $1.12,95 \%$ CI 0.88 to 1.44 ), (adjusted OR $0.97,95 \%$ CI 0.77 to 1.23 ), (adjusted HR 0.62, 95\% CI 0.34 to 1.14 ).

Conclusions: In the most comprehensive analysis of all available data to date, treatment with RAS inhibitors was not associated with increased risk of infection, severity of disease, or 
medRxiv preprint doi: https://doi.org/10.1101/2020.10.03.20206375; this version posted December 3, 2020. The copyright holder for this preprint (which was not certified by peer review) is the author/funder, who has granted medRxiv a license to display the preprint in perpetuity.

It is made available under a CC-BY-NC-ND 4.0 International license .

ACEi/ARB use in COVID-19 pandemic_V8 $\quad 3$ / 31

mortality due to COVID-19. The best available evidence suggests that these treatments should not be discontinued on the basis of concern about risk associated with COVID-19.

Keywords: COVID-19, Renin angiotensin system inhibitors, Susceptibility, Severity, Mortality. 


\section{Introduction}

Following the onset of the COVID-19 pandemic, the observation that angiotensin-converting enzyme 2 (ACE2) was the binding site through which SARS-CoV-2 gained cellular entry ${ }^{1}$, prompted much speculation about the safety of renin angiotensin system (RAS) inhibitors, such as angiotensin converting enzyme inhibitors (ACEi) or angiotensin receptor blocker (ARBs). This concern arose because previous studies had suggested that RAS inhibitors may lead to increased ACE2 expression on the cell surface ${ }^{2}$, and it was assumed that this might increase the susceptibility of patients using these medications to SARS-CoV-2 infection and when infected, increase the risk of an adverse outcome from COVID-19.

RAS inhibitors are widely used to treat patients with hypertension, heart failure, chronic kidney disease and diabetes, all of which are co-morbidities associated with more severe disease and a worse outcome from COVID-19. These concerns led to many patients at risk of severe COVID-19 infection due to these co-morbidities, to discontinue their treatment with RAS inhibitors. This prompted several professional medical and scientific societies to caution against withdrawing RAS inhibitors therapy, whilst acknowledging that more data was needed. ${ }^{3}$ Other commentators suggested a pragmatic solution to continue ACEi or ARBs in patients at highest short term cardiovascular risk but consider stopping these treatments in the majority of patients at lower CVD risk, if they tested positive for Covid-19.

Subsequently, a series of impressive observational and case-controlled studies rapidly emerged that have provided some reassurance about the safety of RAS inhibitors in the context of COVID-19 infection. However, the studies vary in size and region and no individual study has been able to address all of the key questions about the potential impact of 
RAS inhibitors on the susceptibility to SARS-CoV-2 infection, the severity of infection and

risk of mortality. Moreover, questions have remained about the impact of hypertension per se on the risk of COVID-19 and the impact of RAS inhibitors in this large cohort of patients. We therefore undertook a systematic review and meta-analysis of all existing clinical data to provide the most definitive report to date on the association between RAS inhibitors and the susceptibility to SARS-CoV-2 infection (18 studies), the severity of the resulting disease (29 studies) and mortality (30 studies) due to COVID-19.

\section{Methods}

This meta-analysis was conducted in accordance with the Preferred Reporting Items for Systematic Reviews and Meta-analyses Protocols (PRISMA) ${ }^{5}$ and the Meta-analysis of Observational Studies in Epidemiology guidelines (MOOSE). ${ }^{6}$

\section{Eligibility criteria, search strategy and study selection}

We performed a systematic literature search for studies of any design and in any setting in electronic bibliographic databases including PubMed, Web of Science, OVID Embase, and Scopus from Jan $1^{\text {st }}, 2020$ to July $20^{\text {th }}, 2020$, using a comprehensive search strategy as described in eAppendix 1 in the Supplement. We also manually searched preprint platforms (MedRxiv and BioRxiv), coronavirus resource centers of N Engl J Med, JAMA, BMJ and the Lancet, and checked reference lists of eligible studies to find additional studies. We limited our search by language (English). Since COVID-19 topic was a novel disease, any study that reported the associations of the susceptibility to infection with SARS-CoV-2 and severity and 
Y.Z.) independently screened and examined eligible studies. Disagreements were resolved by consensus.

\section{Outcomes}

There were three outcomes of interest; (i) susceptibility to infection with SARS-Cov-2; (ii) the severity of COVID-19 infection; and (iii) mortality from COVID-19. Cases of COVID-19 were defined as those with a positive test result from a real-time reverse-transcriptase-polymerase-chain-reaction (RT-PCR) assay of nasopharyngeal swab samples. Definitions of disease severity of COVID-19 varied among studies (eTable 4 in the Supplement) and it was not feasible to provide a single consistent definition. Most studies from China used the National Health Commission of China guideline, which categorized patients into four types of severity (mild, common, severe, and critical). In these Chinese studies, severe and critical were classified as severe cases and mild and common as non-severe cases. The other studies defined severe cases as admission to an ICU and/or death and/or long hospitalization (eTable 4 in the Supplement). We pooled the result across all included studies based on different definitions of severity and performed subgroup analyses according to the countries of origin (China and Non-China).

\section{Data extraction and risk of bias}

Two reviewers (S.Y. and Y.Z.) independently extracted study data and evaluated studies for risk of bias. The following information was extracted from each study: study identifier, study design, country, study size, mean/median age, male sex proportion, quantitative outcomes, 
effect estimators (Odds ratios [ORs] or Hazard ratios [HRs]) and adjusted covariates if available. The comparison of outcomes comparing ACEi or ARB treatment with non-ACEi or ARB treatment was our primary interest, but several included studies reported data for ACEi and ARB separately. For those studies, we used the additional data for ACEi and ARB to calculate the corresponding data for ACEi or ARB as a single entity, which was a reasonable approach considering the very small possibility of combined use of ACEi and ARB in clinical practice.

Newcastle-Ottawa Scale (NOS) ${ }^{7}$ was used to evaluate the risk of bias (or quality) of each observational study. NOS was calculated according to three major components: selection (0-4 points), comparability (0-2 points) and outcome (0-3 points). A total score of 7 or more was considered as low risk of bias. We planned to use the Cochrane Risk of Bias tool to evaluate the risk of bias in any randomized clinical trials (RCTs), but only one retrospective interim analysis of an unfinished RCT study was identified for this meta-analysis which was treated as a cohort study and evaluated with NOS.

\section{Statistical analysis}

The primary analysis estimated the associations of susceptibility to infection with

SARS-Cov-2 and the severity and mortality from COVID-19 with the use of ACEi or ARB.

Pooled unadjusted ORs were calculated with the Mantel-Haenszel method with a random-effects or fixed-effects model (wherever appropriate), pooled adjusted ORs were calculated with the generic inverse variance method with a random-effects or fixed-effects model. In terms of mortality, some studies reported ORs, others reported HRs, thus we pooled 
ORs and HRs separately. We performed a series of subgroup analyses in hypertensive patients,

Chinese/non-Chinese, case-controlled studies, and non-severe and severe patients, wherever data was available for the three outcomes of interest. Additionally, we calculated the pooled estimates for outcomes with ACEi and ARB separately.

Inter-study heterogeneity was assessed with the $\chi^{2}$ based-Q-statistic test and $\mathrm{I}^{2}$ statistic. $\mathrm{I}^{2}<$ $25 \%, 25 \%-50 \%$ and $>50 \%$ suggested low, moderate, and high heterogeneity, respectively. We examined the potential publication bias using Funnel plots and Egger's test. Leave-one-out sensitivity analyses were applied to evaluate the robustness of our findings after excluding each included study on the pooled results. All statistical analyses were conducted using Reviewer Manager 5.3 (The Nordic Cochrane Center, The Cochrane Collaboration, 2018, Copenhagen, Denmark) and STATA version 12.0 (Stata Corp., College Station, TX).

\section{Patients and Public Involvement:}

This was a systematic review and meta-analysis of previously published data and there was no involvement of patients or the public in this study.

\section{Results}

The search strategy identified 536 published articles from the PubMed, 600 from the Web of Science, 424 from the OVID Embase and 390 from the Scopus, and 24 electronically published articles from the preprint platforms (Figure 1). After duplication and eligibility screening, 81 articles remained. 23 articles were further omitted because of unrelated topic, unavailable or overlapping data, ineligible design, or journal retraction. A total of 58 studies 
HRs).

The Table describes the cohort characteristics of the included studies. Our analysis comprised 69,200 COVID-19 patients and 3,103,335 controls from 58 studies ( 35 published in journals and 23 available as preprints via MedRxiv). Since not all studies provided three major outcomes of interest i.e. susceptibility to infection, disease severity and mortality, we collated the studies into 3 groups, according to the availability of data for the three major outcomes (Table).

\section{Use of RAS inhibitors and susceptibility to infection with SARS-Cov-2}

Eighteen studies $(3,128,679$ participants) were included in the susceptibility analysis, of which 7 reported adjusted ORs and 3 reported adjusted HRs. The adjustment strategies for individual studies are listed in the Table. There was no significant difference in the incidence of COVID-19 infection between RAS inhibitor users and non-users, before and after adjustment (unadjusted OR 1.05, 0.90 to 1.21 ; adjusted OR 0.93, 0.85 to 1.02; adjusted HR $1.07,0.87$ to 1.31 ; Figure 2.)

\section{Use of RAS inhibitors and the severity of COVID-19}

We assessed the Covid-19 case severity from 29 studies, including 18,959 COVID-19 patients, of which 3840 were severe cases (20.3\%). Adjusted ORs were reported for 13 studies and adjusted HRs were reported for 1 study. The definitions of severe COVID-19 are listed in eTable 4 in the Supplement. There was no significant difference in severe case rate between 
confounders (OR 0.76, 0.52 to 1.12 ), especially age and gender (Figure 3).

\section{Use of RAS inhibitors and mortality from COVID-19}

30 studies were included in the unadjusted analysis and 11 studies in the adjusted analysis of mortality from COVID-19 (8 with adjusted ORs and 3 with adjusted HRs). In 33,441

COVID-19 patients, 4234 deaths (12.7\%) occurred. There was no significant difference in the mortality between RAS inhibitor users and non-users before (OR 1.12, 0.88 to 1.44) and after adjustment for age, gender and other covariates (OR 0.97, 0.77 to 1.23, Figure 4). Three studies reported adjusted HRs, for which the pooled HR showed no difference in mortality in RAS inhibitor users when compared with non-users in COVID-19 patients (HR 0.62, 0.34 to 1.14).

\section{Subgroup analyses:}

\section{A comparison of the association of ACEi versus ARB with susceptibility and severity of COVID-19}

When ACEi and ARB were analyzed separately (eFigures 1 and 2 in the Supplement), before and after adjustment for confounders, there was no significant difference in the incidence of COVID-19 infection between ACEi users and non-users (unadjusted OR 0.94, 0.89 to 1.00 and adjusted OR 0.90, 0.79 to 1.04) or between ARB users and non-users (unadjusted OR $1.05,1.00$ to 1.11 and adjusted OR $1.12,0.96$ to 1.32 ). There was also no difference in the severe case rate between ACEi users and non-users (OR 0.93, 0.59 to 1.48), or between ARB users and non-users (OR 0.91, 0.71 to 1.17, eFigure 3 in the Supplement). When COVID-19 


\section{Impact of RAS inhibitor use in patients with hypertension on susceptibility to}

\section{Covid-19 and disease severity}

In the susceptibility analysis without adjustment, 4 studies reported data specifically in hypertensive patients (eFigure 5 in the Supplement). There was no difference in the incidence of COVID-19 infection between RAS inhibitor users and non-users (OR 1.13, 0.80 to 1.61) in patients with hypertension. Similar findings were observed after adjustment (OR 0.87, 0.73 to 1.04, eFigure 6 in the Supplement).

Seventeen studies reported unadjusted data on disease severity in hypertensive COVID-19 patients and there was no difference in the severe case rate between RAS inhibitor users and non-users (OR 0.82, 0.63 to 1.06). Similarly, in 6 studies that reported adjusted ORs, there was also no significant difference after adjustment, with a OR 0.64 (0.40 to 1.02) (eFigure 6 in the Supplement).

Ten studies reported mortality in hypertensive COVID-19 patients and there was no difference in mortality between RAS inhibitor users and non-users before (OR $0.83,0.60$ to 1.13, eFigure 5 in the Supplement) and after adjustment (OR 0.93, 0.61 to 1.42 and HR 0.61, 0.33 to 1.12 , eFigure 6 in the Supplement) 


\section{Association of susceptibility of COVID-19 with use of RAS inhibitors in}

\section{case-controlled studies}

Eight case-controlled studies and eleven retrospective cohort studies reported the susceptibility data without adjustment, which showed no difference in the incidence of COVID-19 infection between RAS inhibitor users and non-users, with OR 0.95, 0.78 to 1.15 and OR 1.14, 0.90 to 1.43 , respectively, eFigure 7 in the Supplement).

\section{Association of severity of COVID-19 with use of RAS inhibitors in Chinese and non-Chinese cohort}

There were 12 studies reporting the severity data in Chinese cohorts without adjustment (eFigure 8 in the Supplement), which showed no difference in the incidence of severe case rate between Chinese RAS inhibitor users and non-users before (OR 0.79, 0.57 to 1.09, eFigure 8 in the Supplement) and after adjustment (OR 0.54, 0.23 to 1.26, eFigure 9 in the Supplement). In 14 studies in the non-Chinese cohorts, RAS inhibitor users had a higher severity rate than non-users before adjustment for confounders (OR 1.41, 1.02 to 1.96, eFigure 8 in the Supplement), but after adjustment, the associations were not significant (OR $0.80,0.53$ to 1.20 , eFigure 9 in the Supplement).

\section{Association of susceptibility and severity of COVID-19 with hypertension status}

After adjustment for confounders, hypertension was not associated with the increased susceptibility to COVID-19 (OR $1.09,0.95$ to 1.25 ). Hypertension was significantly associated with the increased Covid-19 severity rate (OR 1.44, 1.10 to 1.89 ) and increased mortality after adjustment (HR 2.14, 1.46 to 3.14; eFigure 10 in the Supplement). However, when we included recently published UK national data $(n=17,278,392)$ which focused on the 
COVID-19 mortality, with a HR 1.53, 0.78 to 2.99 (eFigure 10 in the Supplement).

\section{Sensitivity Analyses and Risk of Bias}

The main outcomes of this meta-analysis remained unaltered in the sensitivity analysis by excluding each individual study. Considering the retrospective and observational setting for all of these studies, the risk of bias was high (eTables 1-3 in the Supplement) and the $\mathrm{I}^{2}$ values were large in some pooled analyses. However, Funnel plots and Egger's test indicated that there was no substantial publication bias (eFigures 11-13 in the Supplement).

\section{Discussion}

In this systematic review and meta-analysis of observational and case-controlled studies, the use of RAS inhibitors was not associated with increased susceptibility to infection with SARS-CoV-2 and was not associated with increased risk of severe disease or mortality from COVID-19. Moreover, when ACEi or ARB were analyzed separately versus non-users of these drugs, there was no evidence that either treatment's association with susceptibility, severe disease or death from COVID-19 was different from the other when compared to non-users. Similar results were obtained when specifically examining RAS inhibitor users versus non-use in people with hypertension, or when comparing Chinese and non-Chinese patient cohorts and when the analysis was restricted to case-controlled studies.

Due to the fact that the earliest studies characterizing co-morbidities most likely to be associated with poor outcomes from COVID-19, cited pre-existing hypertension as one of the 
most important, ${ }^{9}$ we also examined whether hypertension was independently associated with increased susceptibility to infection with SARS-CoV-2 and increased risk of severe disease or mortality in those infected. Mindful of how common hypertension is and its strong association with ageing, we had concerns that the Covid-19 risk associated with hypertension might have been exaggerated because the earliest reports had not been adjusted for potential confounding, especially age, the latter being a potent risk factor for death from COVID-19. ${ }^{8}$ Thus, it was important to examine the association between COVID-19 and hypertension independent of age, other demographics, and comorbidities. Our pooled studies with available data on hypertension (6 studies for susceptibility) showed no significant independent association between hypertension and susceptibility to SARS-CoV-2 infection. However, we did find a significant association between hypertension and case severity and mortality from Covid-19. Subsequently, we incorporated a new analysis by Williamson et $\mathrm{al}^{8}$, of the relationship between patient demographics and comorbidities (including hypertension) and Covid-19 mortality in 17 million people in the UK. The addition of this data to our analysis, attenuated the association between hypertension and mortality, however, the pooled results still revealed a trend towards an approximately $50 \%$ increased probability of an adverse outcome in patients with hypertension, although the corresponding confidence interval crossed the reference line. Interestingly, the report of Williamson et $\mathrm{al}^{8}$, reveals the complexity and the importance of confounding in the relationships between hypertension and Covid-19 outcomes. Notably that much of the risk association between hypertension and Covid-19 outcomes could be accounted for by age, diabetes and obesity, which are all independent risk factors for poorer outcomes and are commonly associated with hypertension. There was also an 

and activity of ACE2, the availability of angiotensin II at the AT-2 receptor and the angiotensin II cleavage product, angiotensin 1-7. Hypotheses have been presented to explain how these differential effects of ACEi and ARBs could influence the susceptibility to SARS-CoV-2 infection and/or severity and mortality from COVID-19. For the purposes of our analysis, many studies reported results with ACEi and ARB separately and we found that the pooled results of either ACEi or ARB showed no association with COVID-19 for any outcomes of interest. One study directly compared the effects of ACEi and ARB on mortality from COVID-19. By comparing 124 COVID-19 patients taking ACEi with 248 matched patients taking ARB, no significant difference in 28-day all-cause mortality were found between groups. ${ }^{10}$ Our findings suggest that there neither RAS-inhibition overall, or ACEi or ARB treatment individually are associated with increased risk from COVID-19.

The concept that ACEi or ARB might increase the risk of infection or severity of COVID-19 arose from the observation that ACE2 is the binding site that facilitates the cellular entry of SARS-CoV-2. This led to speculation that treatment with RAS inhibitor drugs might increase 
the cellular expression of ACE2 and thereby increase the risk of infection and severity of disease. This speculation cited previous experimental studies that had shown that RAS inhibitor could increase the expression of ACE2 in heart and kidney ${ }^{2}$, however, there was no data on the effect of RAS inhibitors on lung ACE2 expression in either animals or human. Moreover, the concept that RAS inhibitors increases ACE2 expression is now being contested. A recent study, Sama et al. ${ }^{11}$ showed that use of an ACEi or an ARB was not associated with higher plasma ACE2 concentrations. Whilst circulating ACE2 may not be a good indicator of tissue ACE2 levels, other recent evidence suggests that there is increasing expression of ACE2 with age in both human lungs and kidney but no association between the expression of ACE2 with either hypertension or RAS inhibiting drugs. ${ }^{12}$ Thus, the hypothesis that RAS inhibitors could increase risk from COVID-19 by increasing ACE2 expression is unsupported by the limited pathophysiological data available, or the more extensive clinical data from the cohort studies of patients included in this meta-analysis. This in turn, reinforces the recommendations made by medical societies, for patients to continue with their RAS inhibitor medications throughout this COVID-19 pandemic. $^{3}$

The present finding needs to be interpreted, mindful of the limitations of observational cohort studies. It is noteworthy that in most analyses, there is substantial risk of bias indicated by the high $\mathrm{I}^{2}$ value in both main and subgroup analyses. This was mainly attributable to the inherent weakness of observational studies and the inevitable possibility of confounding. The association of various outcomes or with prior pharmaceutical treatments are commonly influenced by numerous confounders, especially the indication for treatment, which often varies according to comorbidities. The fact that RAS inhibitor medications are recommended 
as a foundation treatment for hypertension or many of the comorbidities associated with increased risk of mortality from COVID-19, i.e. diabetes, cardiac disease and chronic kidney disease, and the fact that all of these conditions are more common with advancing age, highlights the obvious potential for confounding in the relationship between RAS inhibitor use and adverse outcomes from COVID-19. These confounding can only really be overcome by randomized allocations to treatments in controlled trials and such trials are ongoing. ${ }^{13}$

\section{Conclusions}

In this systematic review and meta-analysis of all existing clinical data during the Covid-19 pandemic, we found that treatment with RAS inhibitors, specifically ACEi or ARBs, was not associated with increased risk of infection with SARS-CoV-2, or increased risk for the development of severe disease, or mortality from COVID-19, when compared to non-users of RAS inhibition. Our study suggests that ACEi or ARBs should not be discontinued solely on the basis of concerns about potential risks associated with COVID-19. 
Decalarations of Interests: BW has received honoraria for lectures on the treatment of

hypertension and cardiovascular risk from Daiichi Sankyo, Servier, Pfizer, Novartis and

Menarini; The other authors have no declarations of interest in relation to the submitted work.

Author Contributions: YZ and BW conceived the idea for the study and the analysis plan.

YZ and SY performed the data extractions and analyses, supervised by YX. YZ and BW

drafted the manuscript with critical input from SY and YZ.

Funding sources: BW is supported by the NIHR University College London Biomedical

Research Centre. YZ is supported by the National Nature Science Foundation of China

(81670377) and the Shanghai Excellent Young Scholars Program (2017YQ065). 


\section{References:}

1. Zhou P, Yang XL, Wang XG, et al. A pneumonia outbreak associated with a new coronavirus of probable bat origin. Nature. Mar 2020;579(7798):270-273.

2. Ferrario CM, Jessup J, Chappell MC, et al. Effect of angiotensin-converting enzyme inhibition and angiotensin II receptor blockers on cardiac angiotensin-converting enzyme 2. Circulation. May 24 2005;111(20):2605-2610 Ishiyama Y, Gallagher PE, Averill DB, Tallant EA, Brosnihan KB, Ferrario CM. Upregulation of angiotensin-converting enzyme 2 after myocardial infarction by blockade of angiotensin II receptors. Hypertension. May 2004;43(5):970-976 Soler MJ, Ye M, Wysocki J, William J, Lloveras J, Batlle D. Localization of ACE2 in the renal vasculature: amplification by angiotensin II type 1 receptor blockade using telmisartan. Am J Physiol Renal Physiol. Feb 2009;296(2):F398-405.

3. European Society of Cardiology. Position statement of the ESC Council on Hypertension on ACE-inhibitors and angiotensin receptor blockers. 2020; https://www .escardio .org/Councils/ Council on Hypertension (CHT)/ News/position statement of the ESC council on hypertension on ACE inhibitors and ANG. Accessed 12 June, 2020 American College of Cardiology.

HFSA/ACC/AHA statement addresses concerns re: using RAAS antagonists in COVID-19. 2020; https://www .escardio .org/Councils/ Council on Hypertension (CHT)/ News/position statement of the ESC council on hypertension on ACE inhibitors and ANG. Accessed 12 June, 2020.

4. Aronson JK, Ferner RE. Drugs and the renin-angiotensin system in covid-19. Bmj. Apr 2 2020;369:m1313.

5. Hutton B, Salanti G, Caldwell DM, et al. The PRISMA extension statement for reporting of systematic reviews incorporating network meta-analyses of health care interventions: checklist and explanations. Ann Intern Med. Jun 2 2015;162(11):777-784.

6. Stroup DF, Berlin JA, Morton SC, et al. Meta-analysis of observational studies in epidemiology: a proposal for reporting. Meta-analysis Of Observational Studies in Epidemiology (MOOSE) group. Jama. Apr 19 2000;283(15):2008-2012.

7. Wells G A SB, Peterson J, Welch V, Losos M, Tugwell P. The Newcastle-Ottawa Scale (NOS) for assessing the quality of nonrandomised studies in meta-analyses. http://www.ohri.ca/programs/clinical_epidemiology/oxford.asp. Accessed 20 June, 2020.

8. Williamson EJ, Walker AJ, Bhaskaran K, et al. Factors associated with COVID-19-related death using OpenSAFELY. Nature. 2020/07/08 2020.

9. Wang D, Hu B, Hu C, et al. Clinical Characteristics of 138 Hospitalized Patients With 2019 Novel Coronavirus-Infected Pneumonia in Wuhan, China. Jama. Feb 7 2020;323(11):1061-1069 Guan WJ, Ni ZY, Hu Y, et al. Clinical Characteristics of Coronavirus Disease 2019 in China. N Engl J Med. Apr 30 2020;382(18):1708-1720.

10. Zhou F, Liu YM, Xie J, et al. Comparative impacts of angiotensin converting enzyme inhibitors versus angiotensin II receptor blockers on the risk of COVID-19 mortality. Hypertension. Jun 3 2020.

11. Sama IE, Ravera A, Santema BT, et al. Circulating plasma concentrations of angiotensin-converting enzyme 2 in men and women with heart failure and effects of renin-angiotensin-aldosterone inhibitors. Eur Heart J. May 14 2020;41(19):1810-1817.

12. Jiang X, Eales JM, Scannali D, et al. Hypertension and renin-angiotensin system blockers are not associated with expression of Angiotensin Converting Enzyme 2 (ACE2) in the kidney. medRxiv. 


\section{0:2020.2005.2019.20106781.}

13. Losartan for Patients With COVID-19 Requiring Hospitalization. https://clinicaltrials.gov/ct2/show/NCT04312009 Losartan for Patients With COVID-19 Not Requiring Hospitalization. https://clinicaltrials.gov/ct2/show/NCT04311177.

14. Amat-Santos IJ, Santos-Martinez S, López-Otero D, et al. Ramipril in High Risk Patients with COVID-19. J Am Coll Cardiol. May 222020.

15. Caraballo C, McCullough M, Fuery M, et al. COVID-19 Infections and Outcomes in a Live Registry of Heart Failure Patients Across an Integrated Health Care System. medRxiv. 2020:2020.2004.2027.20082016.

16. Chang TS, Ding Y, Freund MK, et al. Prior diagnoses and medications as risk factors for COVID-19 in a Los Angeles Health System. medRxiv. 2020:2020.2007.2003.20145581.

17. Chodick G, Nutman A, Yiekutiel N, Shalev V. Angiotension-converting enzyme inhibitors and angiotensin-receptor blockers are not associated with increased risk of SARS-CoV-2 infection. J Travel Med. May 142020.

18. de Abajo FJ, Rodríguez-Martín S, Lerma V, et al. Use of renin-angiotensin-aldosterone system inhibitors and risk of COVID-19 requiring admission to hospital: a case-population study. Lancet. May 30 2020;395(10238):1705-1714.

19. Dublin S, Walker RL, Floyd JS, et al. Renin-angiotensin-aldosterone system inhibitors and COVID-19 infection or hospitalization: a cohort study. medRxiv. 2020:2020.2007.2006.20120386.

20. Raisi-Estabragh Z, McCracken C, Ardissino M, et al. NON-WHITE ETHNICITY, MALE SEX, AND HIGHER BODY MASS INDEX, BUT NOT MEDICATIONS ACTING ON THE RENIN-ANGIOTENSIN SYSTEM ARE ASSOCIATED WITH CORONAVIRUS DISEASE 2019 (COVID-19) HOSPITALISATION: REVIEW OF THE FIRST 669 CASES FROM THE UK BIOBANK. medRxiv. 2020:2020.2005.2010.20096925.

21. Fosbøl EL, Butt JH, Østergaard L, et al. Association of Angiotensin-Converting Enzyme Inhibitor or Angiotensin Receptor Blocker Use With COVID-19 Diagnosis and Mortality. JAMA. 2020;324(2):168-177.

22. Gnavi R, Demaria M, Picariello R, Dalmasso M, Ricceri F, Costa G. Therapy with agents acting on the renin-angiotensin system and risk of SARS-CoV-2 infection. Clin Infect Dis. May 222020.

23. Huh K, Ji W, Kang M, et al. Association of previous medications with the risk of COVID-19: a nationwide claims-based study from South Korea. medRxiv. 2020:2020.2005.2004.20089904.

24. Kim J, Kim DW, Kim K-i, et al. Compliance of Antihypertensive Medication and Risk of Coronavirus Disease 2019: a Cohort Study Using Big Data from the Korean National Health Insurance Service. J Korean Med Sci. 6/ 2020;35(25).

25. Mancia G, Rea F. Renin-Angiotensin-Aldosterone System Blockers and the Risk of Covid-19. Jun 18 2020;382(25):2431-2440.

26. Mehta N, Kalra A, Nowacki AS, et al. Association of Use of Angiotensin-Converting Enzyme Inhibitors and Angiotensin II Receptor Blockers With Testing Positive for Coronavirus Disease 2019 (COVID-19). JAMA Cardiol. May 52020.

27. Morales DR, Conover MM, You SC, et al. Renin-angiotensin system blockers and susceptibility to COVID-19: a multinational open science cohort study. medRxiv. 2020:2020.2006.2011.20125849.

28. Rentsch CT, Kidwai-Khan F, Tate JP, et al. Covid-19 Testing, Hospital Admission, and Intensive Care Among 2,026,227 United States Veterans Aged 54-75 Years. medRxiv. 2020:2020.2004.2009.20059964. 
29. Reynolds HR, Adhikari S, Pulgarin C, et al. Renin-Angiotensin-Aldosterone System Inhibitors and Risk of Covid-19. N Engl J Med. Jun 18 2020;382(25):2441-2448.

30. Shah SJ, Barish PN, Prasad PA, et al. Clinical features, diagnostics, and outcomes of patients presenting with acute respiratory illness: a comparison of patients with and without COVID-19. medRxiv. 2020:2020.2005.2002.20082461.

31. Yan H, Valdes AM, Vijay A, et al. Role of Drugs Affecting the Renin-Angiotensin-Aldosterone System on Susceptibility and Severity of COVID-19: A Large Case-Control Study from Zheijang Province, China. medRxiv. 2020:2020.2004.2024.20077875.

32. Bean D, Kraljevic Z, Searle T, et al. ACE-inhibitors and Angiotensin-2 Receptor Blockers are not associated with severe SARS- COVID19 infection in a multi-site UK acute Hospital Trust. medRxiv. 2020:2020.2004.2007.20056788.

33. Bravi F, Flacco ME, Carradori T, et al. Predictors of severe or lethal COVID-19, including Angiotensin Converting Enzyme inhibitors and Angiotensin II Receptor Blockers, in a sample of infected Italian citizens. PloS one. 2020;15(6):e0235248-e0235248.

34. Choi HK, Koo H-J, Seok H, et al. ARB/ACEI use and severe COVID-19: a nationwide case-control study. medRxiv. 2020:2020.2006.2012.20129916.

35. Chung SM, Lee YY, Ha E, et al. The Risk of Diabetes on Clinical Outcomes in Patients with Coronavirus Disease 2019: A Retrospective Cohort Study. Diabetes Metab J. 6/ 2020;44(3):405-413.

36. Ebinger JE, Achamallah N, Ji H, et al. Pre-Existing Traits Associated with Covid-19 Illness Severity. medRxiv. 2020:2020.2004.2029.20084533.

37. Felice C, Nardin C, Di Tanna GL, et al. Use of RAAS inhibitors and risk of clinical deterioration in COVID-19: results from an Italian cohort of 133 hypertensives. Am J Hypertens. Jun 82020.

38. Feng Y, Ling Y. COVID-19 with Different Severities: A Multicenter Study of Clinical Features. Jun 1 2020;201(11):1380-1388.

39. Gao C, Cai Y, Zhang K, et al. Association of hypertension and antihypertensive treatment with COVID-19 mortality: a retrospective observational study. Eur Heart J. Jun 7 2020;41(22):2058-2066.

40. Hu J, Zhang X, Zhang X, et al. COVID-19 patients with hypertension have more severity condition, and ACEI/ARB treatment have no infulence on the clinical severity and outcome. J Infect. May 282020.

41. Huang Z, Cao J, Yao Y, et al. The effect of RAS blockers on the clinical characteristics of COVID-19 patients with hypertension. Ann Transl Med. Apr 2020;8(7):430.

42. Li J, Wang X, Chen J, Zhang H, Deng A. Association of Renin-Angiotensin System Inhibitors With Severity or Risk of Death in Patients With Hypertension Hospitalized for Coronavirus Disease 2019 (COVID-19) Infection in Wuhan, China. JAMA Cardiol. Apr 232020.

43. Liabeuf S, Moragny J, Bennis Y, et al. Association between renin-angiotensin system inhibitors and COVID-19 complications. Eur Heart J Cardiovasc Pharmacother. Jun 122020.

44. Liu Y, Huang F, Xu J, et al. Anti-hypertensive Angiotensin II receptor blockers associated to mitigation of disease severity in elderly COVID-19 patients. medRxiv.

2020:2020.2003.2020.20039586.

45. López-Otero D, López-Pais J, Cacho-Antonio CE, et al. Impact of angiotensin-converting enzyme inhibitors and angiotensin receptor blockers on COVID-19 in a western population. CARDIOVID registry. Revista Española de Cardiología (English Edition). 2020/06/05/ 2020. 
46. Pan W, Zhang J, Wang M, et al. Clinical Features of COVID-19 in Patients With Essential Hypertension and the Impacts of Renin-angiotensin-aldosterone System Inhibitors on the Prognosis of COVID-19 Patients. Hypertension. Jul 13 2020:Hypertensionaha12015289.

47. Sardu C, Maggi P, Messina V, et al. Could anti-hypertensive drug therapy affect the clinical prognosis of hypertensive patients with COVID-19 infection? Data from centers of southern Italy. J Am Heart Assoc. Jul 7 2020:e016948.

48. Selçuk M, Çınar T, Keskin M, et al. Is the use of ACE inb/ARBs associated with higher in-hospital mortality in Covid-19 pneumonia patients? Clin Exp Hypertens. Nov 16 2020;42(8):738-742.

49. Şenkal N, Meral R, Medetalibeyoğlu A, Konyaoğlu H, Kose M, Tukek T. Association between chronic ACE inhibitor exposure and decreased odds of severe disease in patients with COVID-19. Anatol J Cardiol. Jul 2020;24(1):21-29.

50. De Spiegeleer A, Bronselaer A, Teo JT, et al. The effects of ARBs, ACEIs and statins on clinical outcomes of COVID-19 infection among nursing home residents. medRxiv.

2020:2020.2005.2011.20096347.

51. Xu J, Huang C, Fan G, et al. Use of angiotensin-converting enzyme inhibitors and angiotensin II receptor blockers in context of COVID-19 outbreak: a retrospective analysis. Frontiers of Medicine. 2020/07/03 2020.

52. Yang G, Tan Z, Zhou L, et al. Effects of Angiotensin II Receptor Blockers and ACE (Angiotensin-Converting Enzyme) Inhibitors on Virus Infection, Inflammatory Status, and Clinical Outcomes in Patients With COVID-19 and Hypertension: A Single-Center Retrospective Study. Hypertension. Jul 2020;76(1):51-58.

53. Zhou X, Zhu J, Xu T. Clinical characteristics of coronavirus disease 2019 (COVID-19) patients with hypertension on renin-angiotensin system inhibitors. Clin Exp Hypertens. Oct 2 2020;42(7):656-660.

54. Conversano A, Melillo F, Napolano A, et al. RAAs inhibitors and outcome in patients with SARS-CoV-2 pneumonia. A case series study. Hypertension. May 82020.

55. Baker KF, Hanrath AT, Schim van der Loeff I, et al. COVID-19 management in a UK NHS Foundation Trust with a High Consequence Infectious Diseases centre: a detailed descriptive analysis. medRxiv. 2020:2020.2005.2014.20100834.

56. Benelli G, Buscarini E, Canetta C, et al. SARS-COV-2 comorbidity network and outcome in hospitalized patients in Crema, Italy. medRxiv. 2020:2020.2004.2014.20053090.

57. Cariou B, Hadjadj S. Phenotypic characteristics and prognosis of inpatients with COVID-19 and diabetes: the CORONADO study. May 29 2020:1-16.

58. Chen Y, Yang D, Cheng B, et al. Clinical Characteristics and Outcomes of Patients With Diabetes and COVID-19 in Association With Glucose-Lowering Medication. Diabetes Care. 2020;43(7):1399-1407.

59. Hwang J-m, Kim J-H, Park J-S, Chang MC, Park D. Neurological diseases as mortality predictive factors for patients with COVID-19: a retrospective cohort study. Neurological Sciences. 2020/07/08 2020 .

60. Iaccarino G, Grassi G, Borghi C, Ferri C, Salvetti M, Volpe M. Age and Multimorbidity Predict Death Among COVID-19 Patients: Results of the SARS-RAS Study of the Italian Society of Hypertension. Hypertension. Aug 2020;76(2):366-372.

61. Ip A, Parikh K, Parrillo JE, et al. Hypertension and Renin-Angiotensin-Aldosterone System Inhibitors in Patients with Covid-19. medRxiv. 2020:2020.2004.2024.20077388. 
62. Jung C, Bruno RR, Wernly B, et al. Inhibitors of the Renin-Angiotensin-Aldosterone System and Covid-19 in critically ill elderly patients. Eur Heart J Cardiovasc Pharmacother. Jul 92020.

63. Jung SY, Choi JC, You SH, Kim WY. Association of renin-angiotensin-aldosterone system inhibitors with COVID-19-related outcomes in Korea: a nationwide population-based cohort study. Clin Infect Dis. May 222020.

64. Khera R, Clark C, Lu Y, et al. Association of Angiotensin-Converting Enzyme Inhibitors and Angiotensin Receptor Blockers with the Risk of Hospitalization and Death in Hypertensive Patients with Coronavirus Disease-19. medRxiv. 2020:2020.2005.2017.20104943.

65. Oussalah A, Gleye S, Clerc Urmes I, et al. Long-Term ACE Inhibitor/ARB Use Is Associated with Severe Renal Dysfunction and Acute Kidney Injury in Patients with severe COVID-19: Results from a Referral Center Cohort in the North East of France. Clin Infect Dis. Jul 52020.

66. Richardson S, Hirsch JS, Narasimhan M, et al. Presenting Characteristics, Comorbidities, and Outcomes Among 5700 Patients Hospitalized With COVID-19 in the New York City Area. JAMA. 2020;323(20):2052-2059.

67. Tan ND, Qiu Y, Xing XB, Ghosh S, Chen MH, Mao R. Associations between Angiotensin Converting Enzyme Inhibitors and Angiotensin II Receptor Blocker Use, Gastrointestinal Symptoms, and Mortality among Patients with COVID-19. Gastroenterology. May 152020.

68. Tedeschi S, Giannella M, Bartoletti M, et al. Clinical Impact of Renin-angiotensin System Inhibitors on In-hospital Mortality of Patients With Hypertension Hospitalized for Coronavirus Disease 2019. Clin Infect Dis. Jul 28 2020;71(15):899-901.

69. Zeng Z, Sha T, Zhang Y, et al. Hypertension in patients hospitalized with COVID-19 in Wuhan, China: A single-center retrospective observational study. medRxiv.

2020:2020.2004.2006.20054825. 
medRxiv preprint doi: https://doi.org/10.1101/2020.10.03.20206375; this version posted December 3, 2020. The copyright holder for this preprint (which was not certified by peer review) is the author/funder, who has granted medRxiv a license to display the preprint in perpetuity.

\section{It is made available under a CC-BY-NC-ND 4.0 International license .}

ACEi/ARB use in COVID-19 pandemic_V8 $\quad \mathbf{2 4} / \mathbf{3 1}$

\section{Figure Legends:}

Figure 1. Flowchart of study selection

Figure 2. Pooled unadjusted OR (A) and adjusted OR (B) and adjusted HR (C) for the association of susceptibility of COVID-19 with RAS inhibitor use

Figure 3. Pooled unadjusted (A) and adjusted (B) OR for the association of severe COVID-19 with RAS inhibitor use

Figure 4. Pooled unadjusted OR (A) and adjusted OR (B) and adjusted HR (C) for the association of mortality of COVID-19 with RAS inhibitor use 
ACEi/ARB use in COVID-19 pandemic_V8 $\quad \mathbf{2 5} / \mathbf{3 1}$

\section{Table. Main characteristics of studies included in these analyses}

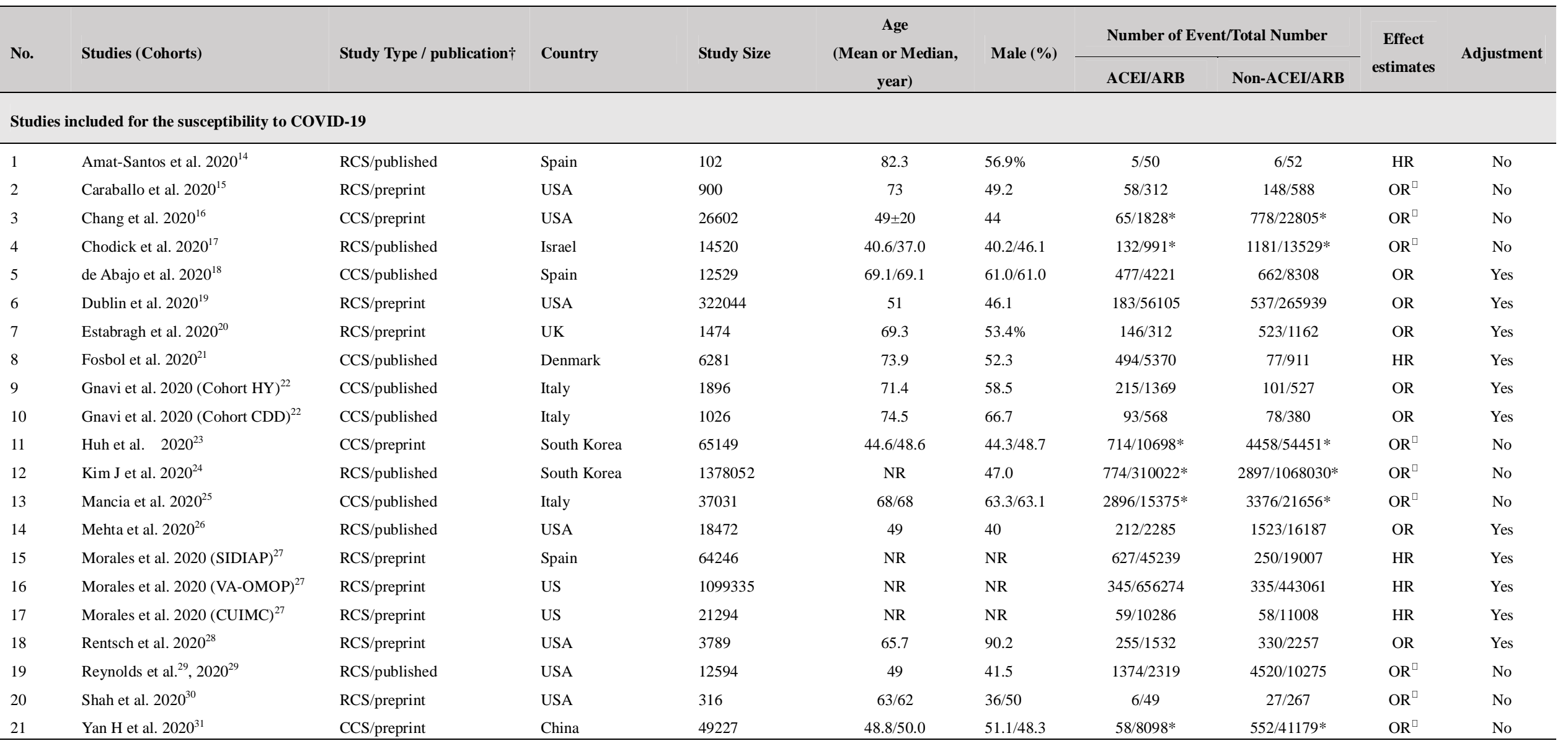

\begin{tabular}{|c|c|c|c|c|c|c|c|c|c|c|}
\hline \multicolumn{11}{|c|}{ Studies included for the severity of COVID-19 } \\
\hline 1 & Bean et al. $2020^{32}$ & RCS/preprint & UK & 1200 & 63 & 57.2 & $127 / 339$ & $288 / 801$ & OR & Yes \\
\hline 2 & Bravi et al. $2020^{33}$ & CCS/published & Italy & 1603 & 58.0 & 47.3 & $104 / 450$ & $88 / 1153$ & $\mathrm{OR}^{\square}$ & No \\
\hline 3 & Chang et al. $2020^{16}$ & CCS/preprint & USA & 220 & 62 & 56 & $6 / 27^{*}$ & $50 / 150 *$ & $\mathrm{OR}^{\square}$ & No \\
\hline 4 & Choi et al. $2020^{34}$ & RCS/preprint & South Korea & 1585 & 66.3 & 42.8 & $34 / 625$ & $55 / 625$ & OR & Yes \\
\hline 5 & Chung et al. $2020^{35}$ & RCS/published & South Korea & 29 & 66.3 & 48.3 & NR & NR & OR & Yes \\
\hline
\end{tabular}


ACEi/ARB use in COVID-19 pandemic_V8 $\quad \mathbf{2 6 / 3 1}$

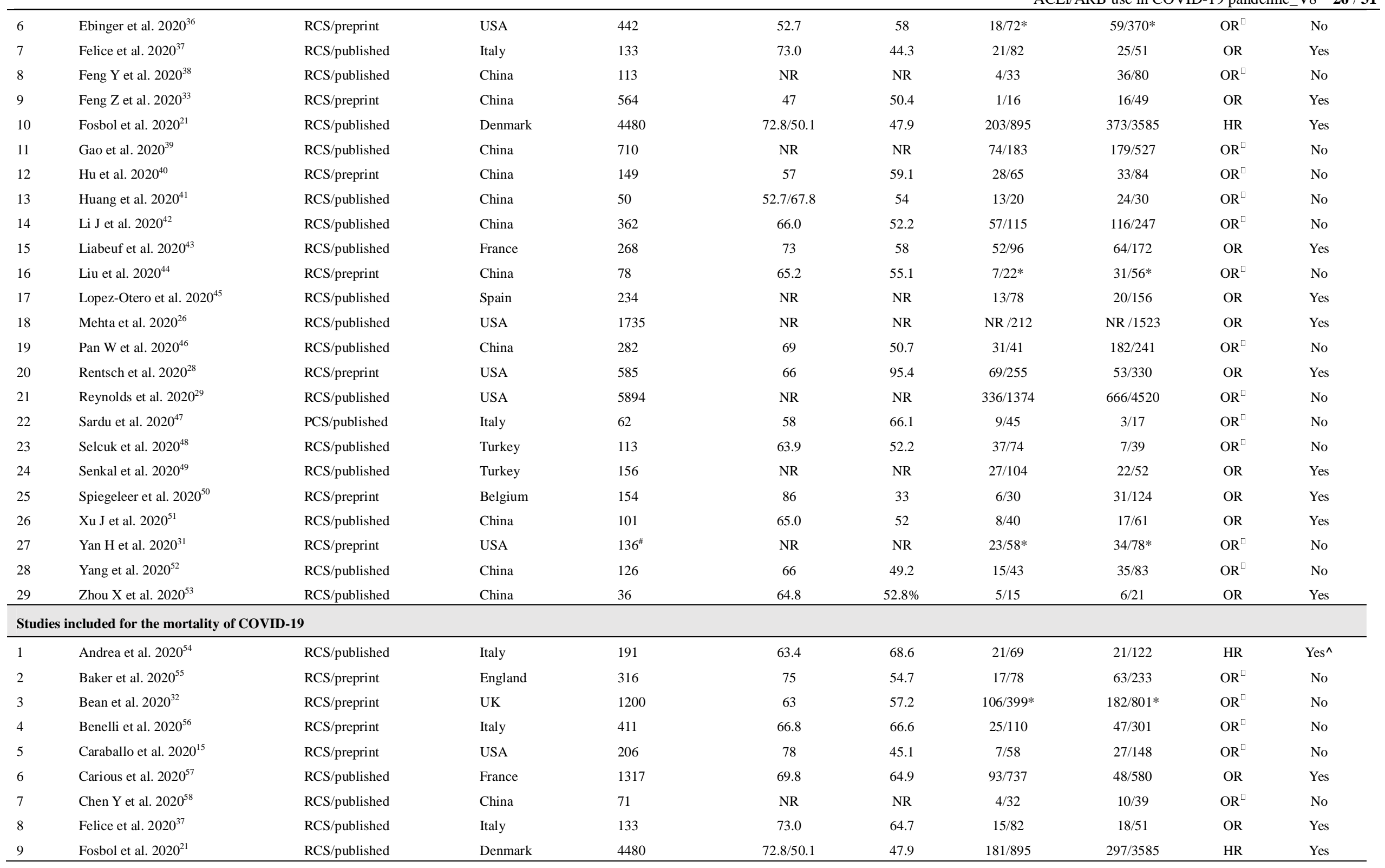


ACEi/ARB use in COVID-19 pandemic_V8 $\quad \mathbf{2 7} / \mathbf{3 1}$

\begin{tabular}{|c|c|c|c|c|c|c|c|c|c|c|}
\hline 10 & Gao et al. $2020^{39}$ & RCS/published & China & 710 & NR & NR & $4 / 183$ & $19 / 527$ & HR & Yes \\
\hline 11 & Hwang et al. $2020^{59}$ & RCS/published & South Korea & 103 & 67.6 & 50.0 & $5 / 13$ & $21 / 90$ & $\mathrm{OR}^{\square}$ & No \\
\hline 12 & Iaccarino et al. $2020^{60}$ & RCS/published & Italy & 1591 & 66.5 & 65.0 & $106 / 655^{*}$ & $82 / 936^{*}$ & $\mathrm{OR}^{\square}$ & No \\
\hline 13 & Ip et al. $2020^{61}$ & RCS/preprint & USA & 1216 & NR & NR & $137 / 460$ & $262 / 669$ & $\mathrm{OR}^{\square}$ & No \\
\hline 14 & Jung $C$ et al. $2020^{62}$ & PCS/published & International & 324 & 75 & 69 & $62 / 157$ & $85 / 167$ & OR & Yes \\
\hline 15 & Jung SY et al. $2020^{63}$ & RCS/published & South Korea & 5179 & 44.6 & 44.0 & $33 / 762$ & $51 / 4417$ & OR & Yes \\
\hline 16 & Khera et al. $2020^{64}$ & RCS/preprint & USA & 7933 & 77 & 45.4 & $664 / 4587$ & $466 / 3346$ & $\mathrm{OR}^{\square}$ & No \\
\hline 17 & Li J et al. $2020^{42}$ & RCS/published & China & 362 & 66 & 52.2 & $21 / 115$ & $56 / 247$ & $\mathrm{OR}^{\square}$ & No \\
\hline 18 & Lopez-Otero et al. $2020^{45}$ & RCS/published & Spain & 965 & 59.5 & 43.9 & $11 / 210$ & $27 / 755$ & OR & Yes \\
\hline 19 & Mehta et al., $2020^{26}$ & RCS/published & USA & 1705 & NR & NR & $8 / 211$ & $34 / 1494$ & $\mathrm{OR}^{\square}$ & No \\
\hline 20 & Pan W et al. $2020^{46}$ & RCS/published & China & 282 & 69 & 50.7 & $4 / 41$ & $63 / 241$ & $\mathrm{OR}^{\square}$ & No \\
\hline 21 & Qussalah et al $2020^{65}$ & RCS/published & France & 149 & 65 & 61 & $10 / 43$ & $9 / 104$ & $\mathrm{OR}^{\square}$ & No \\
\hline 22 & Richardson et al. $2020^{66}$ & RCS/published & USA & 1366 & NR & NR & $130 / 413$ & $254 / 953$ & $\mathrm{OR}^{\square}$ & No \\
\hline 23 & Sardu et al. $2020^{47}$ & PCS/published & Italy & 62 & 58 & 66.1 & $7 / 45$ & $2 / 17$ & $\mathrm{OR}^{\square}$ & No \\
\hline 24 & Selcuk et al. $2020^{48}$ & RCS/published & Turkey & 113 & 63.9 & 52.2 & $31 / 74$ & $4 / 39$ & OR & Yes \\
\hline 26 & Tan et al. $2020^{67}$ & RCS/published & China & 100 & 67 & NR & $0 / 31$ & $11 / 69$ & $\mathrm{OR}^{\square}$ & No \\
\hline 27 & Tedeschi et al. $2020^{68}$ & RCS/published & Italy & 311 & 76 & 72 & NR & NR & OR & Yes \\
\hline 28 & $\mathrm{Xu} \mathrm{J}$ et al. $2020^{51}$ & RCS/published & China & 101 & 65.0 & 52 & $11 / 40$ & $21 / 61$ & OR & Yes \\
\hline 29 & Zeng $\mathrm{Z}$ et al. $2020^{69}$ & RCS/preprint & China & 75 & 67 & 47 & $2 / 28$ & $5 / 47$ & $\mathrm{OR}^{\square}$ & No \\
\hline 30 & Zhou F et al. $2020^{10}$ & RCS/published & China & 3572 & 66 & 51.1 & 70/906 & $272 / 1812$ & HR & Yes \\
\hline
\end{tabular}

$\dagger$ Articles published in print or ahead of print after peer-review were indicated as "published".

* Numbers are calculated by addition of ACEI and ARB.

$\square$ OR calculated according reported numbers of events in case and control groups.

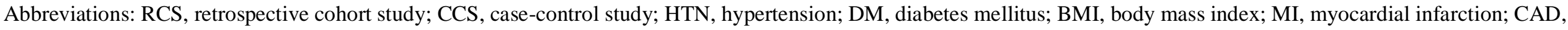
coronary artery disease; NR, not reported. 
medRxiv preprint doi: https://doi.org/10.1101/2020.10.03.20206375; this version posted December 3, 2020. The copyright holder for this preprint (which was not certified by peer review) is the author/funder, who has granted medRxiv a license to display the preprint in perpetuity.

Figure 1
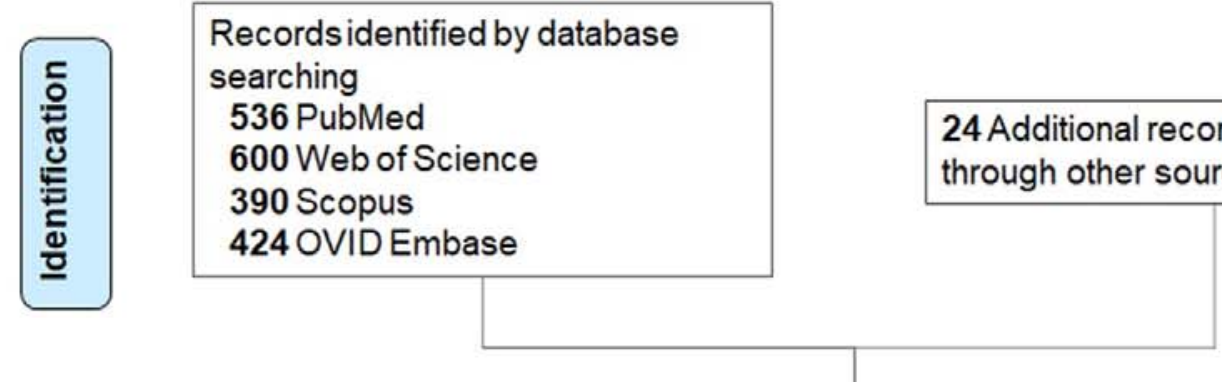
through other sources

\section{1 full text articles screened for eligibility}

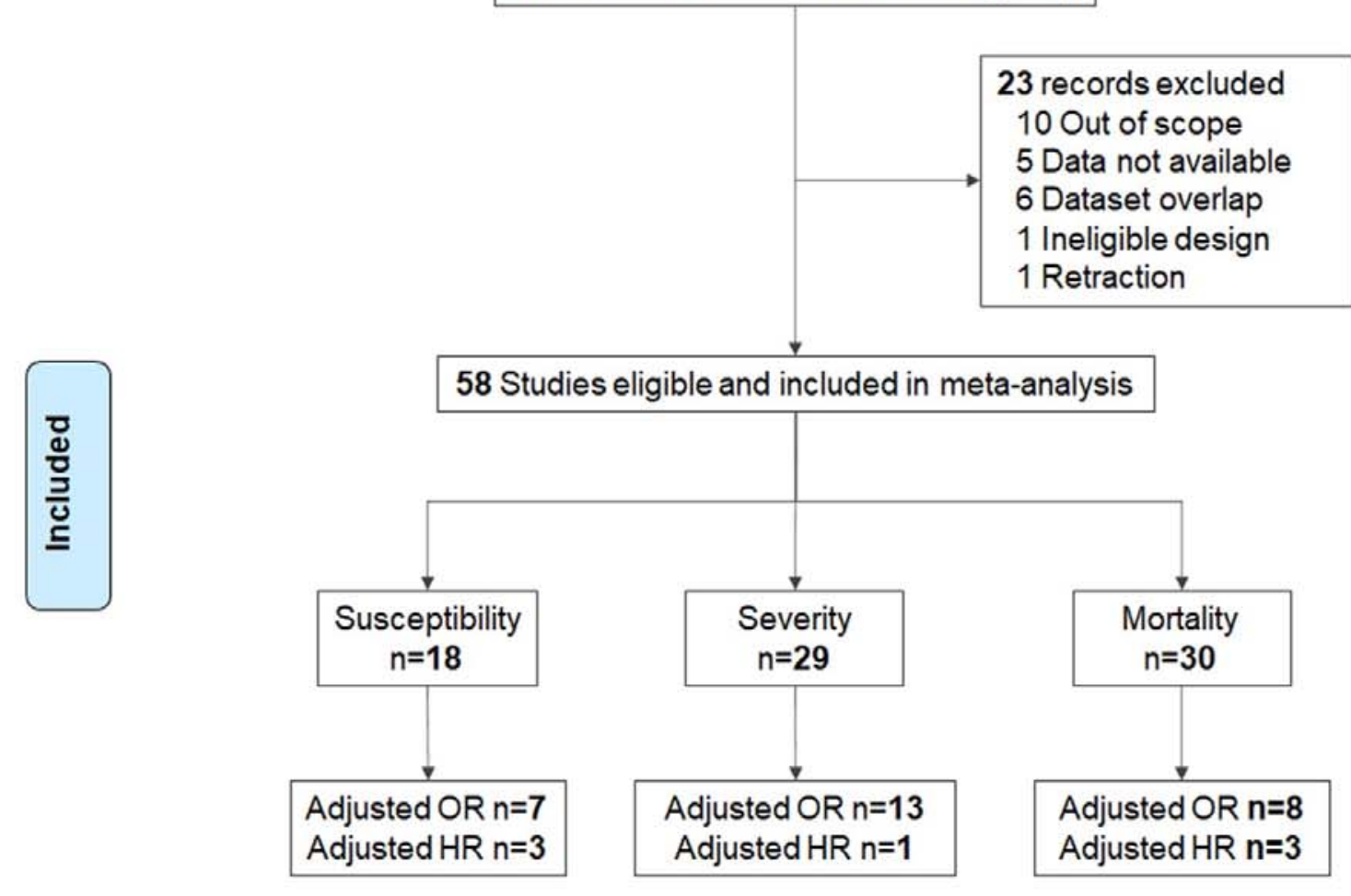


medRxiv preprint doi: https://doi.org/10.1101/2020.10.03.20206375; this version posted December 3, 2020. The copyright holder for this preprint

(which was not certified by peer review) is the author/funder, who has granted medRxiv a license to display the preprint in perpetuity. It is made available under a CC-BY-NC-ND 4.0 International license.

\section{Figure 2}

\section{A}

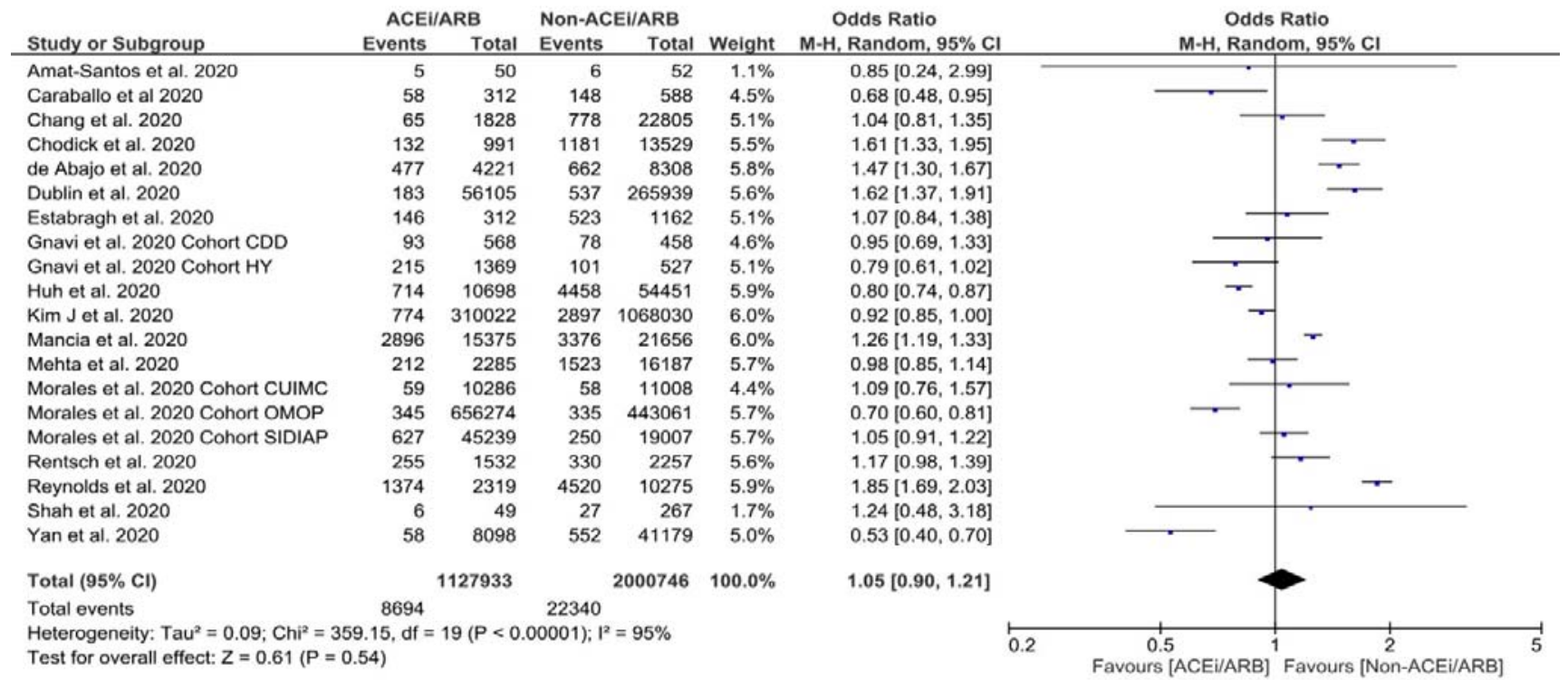

\section{B}

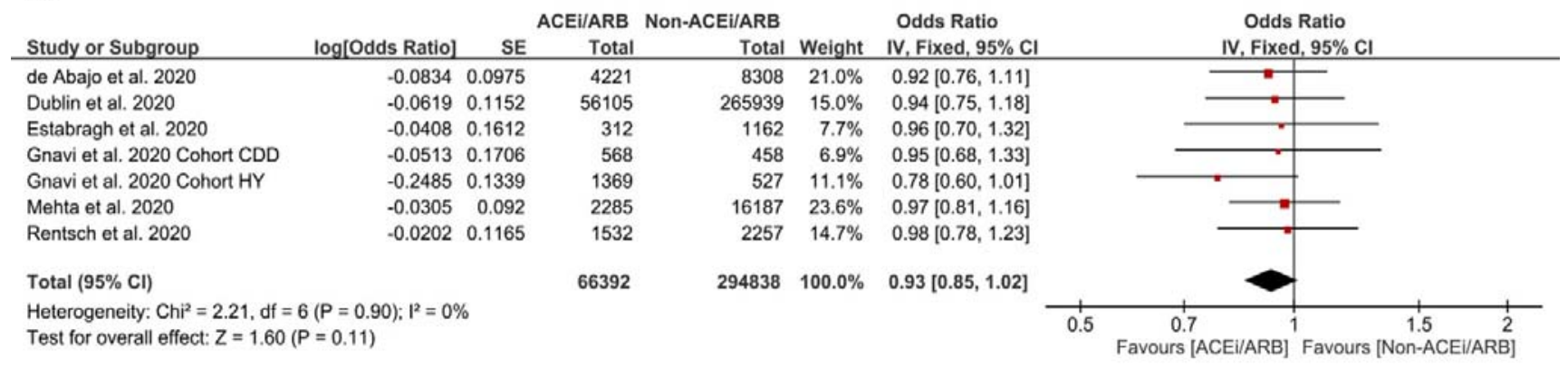

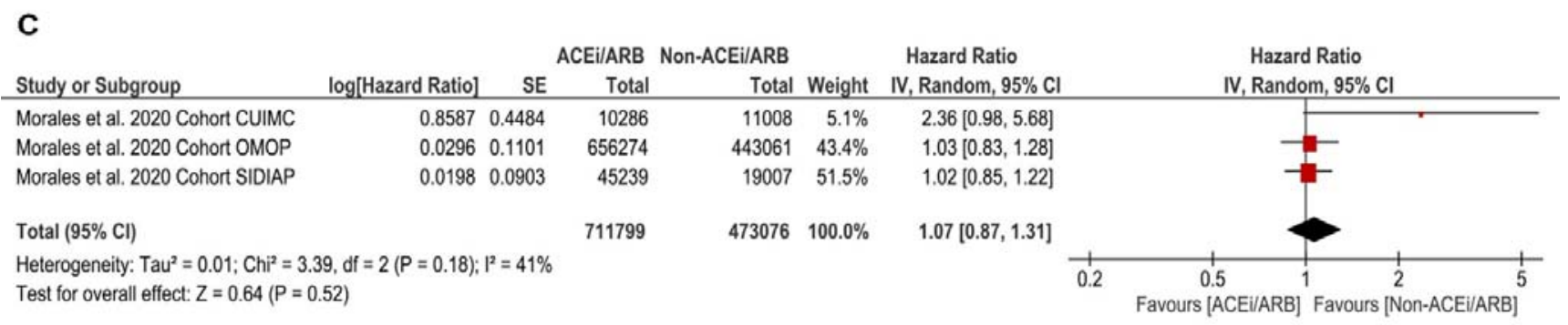


medRxiv preprint doi: https://doi.org/10.1101/2020.10.03.20206375; this version posted December 3, 2020. The copyright holder for this preprint

(which was not certified by peer review) is the author/funder, who has granted medRxiv a license to display the preprint in perpetuity. It is made available under a CC-BY-NC-ND 4.0 International license .

Figure 3

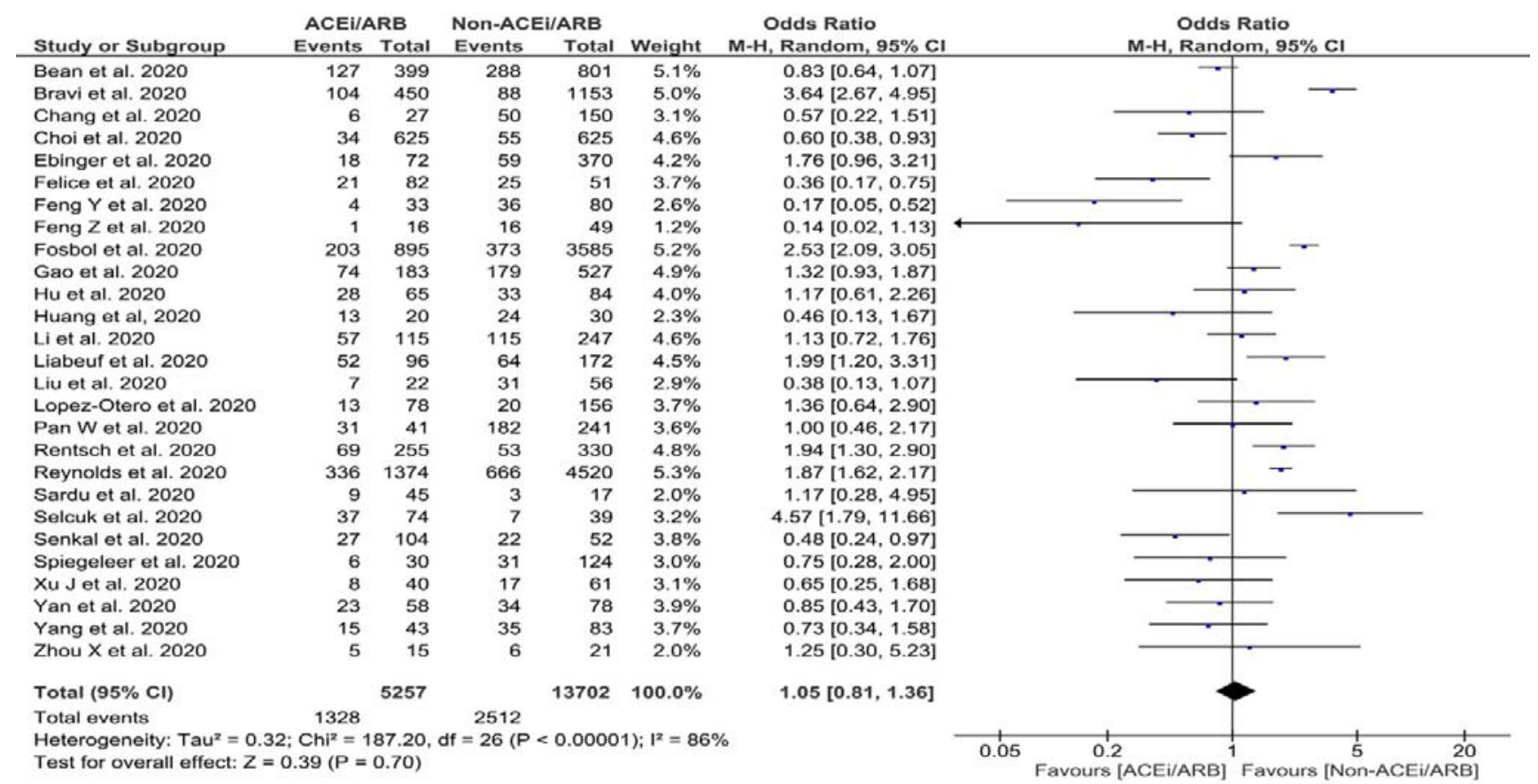

\begin{tabular}{|c|c|c|c|c|c|c|c|c|c|c|}
\hline \multirow{2}{*}{$\begin{array}{l}\text { Study or Subgroup } \\
\text { Bean et al. } 2020\end{array}$} & \multirow{2}{*}{$\begin{array}{r}\text { log[Odds Ratio] } \\
-0.462\end{array}$} & \multirow{2}{*}{$\begin{array}{r}\text { SE } \\
0.1495\end{array}$} & $\begin{array}{l}\text { ACEi/ARB } \\
\text { Total }\end{array}$ & Non-ACEi/ARB & Weight & $\begin{array}{l}\text { Odds Ratio } \\
\text { IV, Random, } 95 \% \mathrm{Cl}\end{array}$ & \multicolumn{4}{|c|}{$\begin{array}{l}\text { Odds Ratio } \\
\text { IV, Random, } 95 \% \mathrm{Cl}\end{array}$} \\
\hline & & & 399 & 801 & $13.0 \%$ & $0.63[0.47,0.84]$ & & $\rightarrow$ & & \\
\hline Choi et al. 2020 & -0.7133 & 0.2503 & 625 & 625 & $11.4 \%$ & $0.49[0.30,0.80]$ & & & & \\
\hline Chung et al. 2020 & -0.5621 & 1.1486 & 0 & 0 & $2.4 \%$ & $0.57[0.06,5.41]$ & & & & \\
\hline Felice et al. 2020 & -1.3863 & 0.5213 & 82 & 51 & $7.1 \%$ & $0.25[0.09,0.69]$ & & & & \\
\hline Feng $Z$ et al. 2020 & -0.8916 & 1.2125 & 16 & 49 & $2.2 \%$ & $0.41[0.04,4.41]$ & & & & \\
\hline Liabeuf et al. 2020 & 0.5481 & 0.2696 & 96 & 172 & $11.1 \%$ & $1.73[1.02,2.93]$ & & & & \\
\hline Lopez-Otero et al. 2020 & -0.1393 & 0.5432 & 78 & 156 & $6.8 \%$ & $0.87[0.30,2.52]$ & & & & \\
\hline Mehta et al. 2020 & 0.4947 & 0.2179 & 212 & 1523 & $12.0 \%$ & $1.64[1.07,2.51]$ & & & $\because$ & \\
\hline Rentsch et al. 2020 & 0.5068 & 0.2902 & 255 & 330 & $10.8 \%$ & $1.66[0.94,2.93]$ & & & & \\
\hline Senkal et al. 2020 & -0.734 & 0.3537 & 104 & 52 & $9.7 \%$ & $0.48[0.24,0.96]$ & & & & \\
\hline Spiegeleer et al. 2020 & -0.734 & 0.8003 & 30 & 124 & $4.2 \%$ & $0.48[0.10,2.30]$ & & & & \\
\hline Xu J et al. 2020 & -0.3857 & 0.4905 & 40 & 61 & $7.5 \%$ & $0.68[0.26,1.78]$ & & & & \\
\hline Zhou $X$ et al. 2020 & -1.9661 & 1.3465 & 15 & 21 & $1.9 \%$ & $0.14[0.01,1.96]$ & $\longleftarrow$ & & & \\
\hline Total $(95 \% \mathrm{Cl})$ & & & 1952 & 3965 & $100.0 \%$ & $0.76[0.52,1.12]$ & & & & \\
\hline \multicolumn{6}{|c|}{$\begin{array}{l}\text { Heterogeneity: } \text { Tau }^{2}=0.28 ; \mathrm{Chi}^{2}=41.26, \mathrm{df}=12(P<0.0001) ; \mathrm{I}^{2}=71 \% \\
\text { Test for overall effect: } Z=1.40(P=0.16)\end{array}$} & & 0.05 & $\begin{array}{c}0.2 \\
\text { Favours IACE }\end{array}$ & 1 Favours [N & $\begin{array}{cr} & 20 \\
\text { Jon-ACEI/ARB] }\end{array}$ \\
\hline
\end{tabular}


medRxiv preprint doi: https://doi.org/10.1101/2020.10.03.20206375; this version posted December 3, 2020. The copyright holder for this preprint

(which was not certified by peer review) is the author/funder, who has granted medRxiv a license to display the preprint in perpetuity. It is made available under a CC-BY-NC-ND 4.0 International license .

ACEi/ARB use in COVID-19 pandemic_V8 $\mathbf{3 1} / \mathbf{3 1}$

\section{Figure 4}

\section{A}

\begin{tabular}{|c|c|c|c|c|c|}
\hline \multirow[b]{2}{*}{ Study or Subgroup } & \multicolumn{2}{|c|}{ ACEi/ARB } & \multicolumn{2}{|c|}{ Non-ACEi/ARB } & \multirow[b]{2}{*}{ Weigh } \\
\hline & Events & Total & Events & Total & \\
\hline Andrea et al. 2020 & 21 & 69 & 21 & 122 & $3.6^{\circ}$ \\
\hline Baker et al. 2020 & 17 & 78 & 63 & 233 & 3.9 \\
\hline Bean et al. 2020 & 106 & 399 & 182 & 801 & $4.8 \%$ \\
\hline Benelli et al. 2020 & 25 & 110 & 47 & 301 & $4.1 \%$ \\
\hline Caraballo et al 2020 & 7 & 58 & 27 & 148 & \\
\hline Carious et al. 2020 & 93 & 737 & 48 & 580 & \\
\hline Chen $Y$ ot al. 2020 & 4 & 32 & 10 & 39 & $2.2^{\circ}$ \\
\hline Felice et al. 2020 & 15 & 82 & 18 & 51 & $3.3^{\circ}$ \\
\hline Fosbol et al. 2020 & 181 & 895 & 297 & 3585 & 4.5 \\
\hline Gao et al. 2020 & 4 & 183 & 19 & 527 & \\
\hline Hwang et al. 2020 & 5 & 13 & 21 & 90 & 2.3 \\
\hline laccarino et al. 2020 & 106 & 655 & 82 & 936 & 4.7 \\
\hline Ip et al. 2020 & 137 & 460 & 262 & 669 & 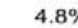 \\
\hline Jung C et al. 2020 & 62 & 157 & 85 & 167 & 4.2 \\
\hline Jung SY et al. 2020 & 33 & 762 & 51 & 4417 & 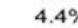 \\
\hline Khera et al. 2020 & 664 & 4587 & 466 & 3346 & 5.0 \\
\hline Li et al. 2020 & 21 & 115 & 56 & 247 & 4.0 \\
\hline Lopez-Otero et al. 2020 & 11 & 210 & 27 & 755 & 3.6 \\
\hline Mehta et al. 2020 & 8 & 211 & 34 & 1494 & 3.4 \\
\hline Pan W et al. 2020 & 4 & 41 & 63 & 241 & 2.6 \\
\hline Qussalah et al. 2020 & 10 & 43 & 9 & 104 & 2.8 \\
\hline Richardson et al. 2020 & 130 & 413 & 254 & 953 & 4.8 \\
\hline Sardu et al. 2020 & 7 & 45 & 2 & 17 & \\
\hline Selcuk et al. 2020 & 31 & 74 & 4 & 39 & 2.5 \\
\hline Senkal et al. 2020 & 7 & 104 & 5 & 52 & 2.3 \\
\hline Tan et al. 2020 & 0 & 31 & 11 & 69 & \\
\hline Xu J et al. 2020 & 11 & 40 & 21 & 61 & \\
\hline Zeng $\mathrm{Z}$ et al. 2020 & 2 & 28 & 5 & 47 & 1.5 \\
\hline Zhou F et al. 2020 & 70 & 906 & 272 & 1812 & 4.8 \\
\hline Total $(95 \%$ CI) & & 11538 & & 21903 & \\
\hline Total events & 1792 & & 2462 & & \\
\hline
\end{tabular}

Heterogeneity: Tau $^{2}=0.32 ; \mathrm{Chi}^{2}=234.98, \mathrm{df}=28(\mathrm{P}<0.00001): \mathrm{I}^{2}=88 \%$

Heterogeneity: $\mathrm{Tau}^{2}=0.32$; $\mathrm{Chi}^{2}=234.98$,
Test for overall effect: $Z=0.92(P=0.36)$

Odds Ratio Random, 95\% CI

$2.10[1.05,4.22]$

$0.75[0.41,1.38]$

$1.23[0.93,1.62]$

$1.59[0.92,2.74]$

$0.62[0.25,1.50]$

$1.60[1.11,2.31]$

$0.41[0.12,1.48]$

$0.41[0.18,0.92]$

$2.81[2.29,3.43]$

$0.60[0.20,1.78]$

$2.05[0.61,6.95]$

$2.01[1.48,2.73]$

$0.66[0.51,0.85]$

$0.63[0.41,0.98]$

$3.88[2.48,6.05]$

$1.05[0.92,1.19]$

$0.76[0.44,1.33]$

$1.49[0.73,3.06]$

$1.69[0.77,3.71]$

$0.31[0.10,0.89]$

$3.20[1.20,8.55]$

$1.26[0.98,1.63]$

$1.38[0.26,7.42]$

6.31 [2.03, 19.58]

$0.68[0.20,2.25]$

$0.08[0.00,1.42]$

$0.72[0.30,1.73]$

$0.65[0.12,3.58]$

$0.47[0.36,0.62]$

$1.12[0.88,1.44]$

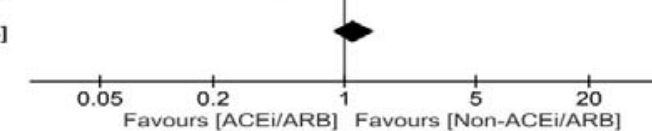

B

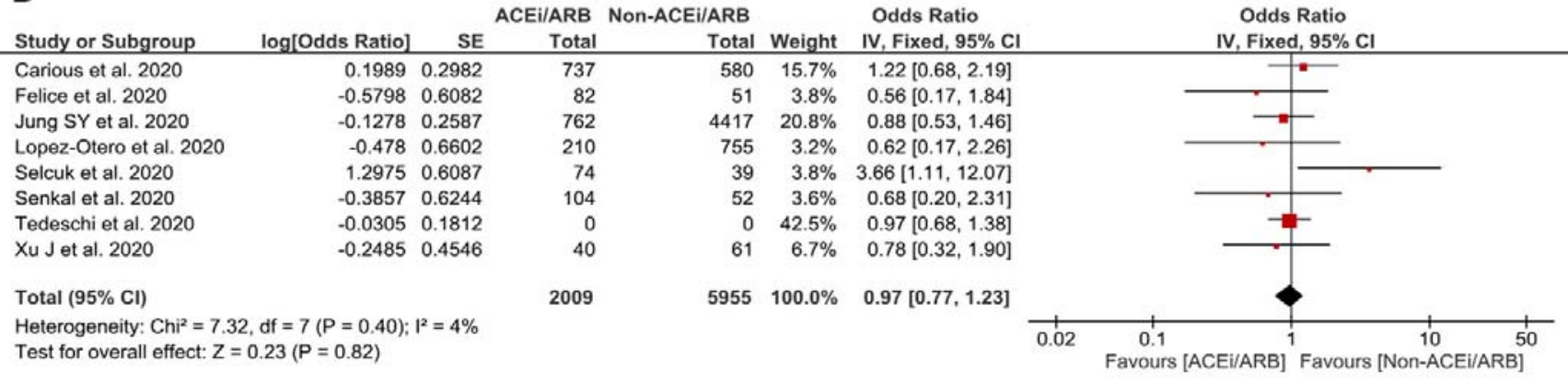

C

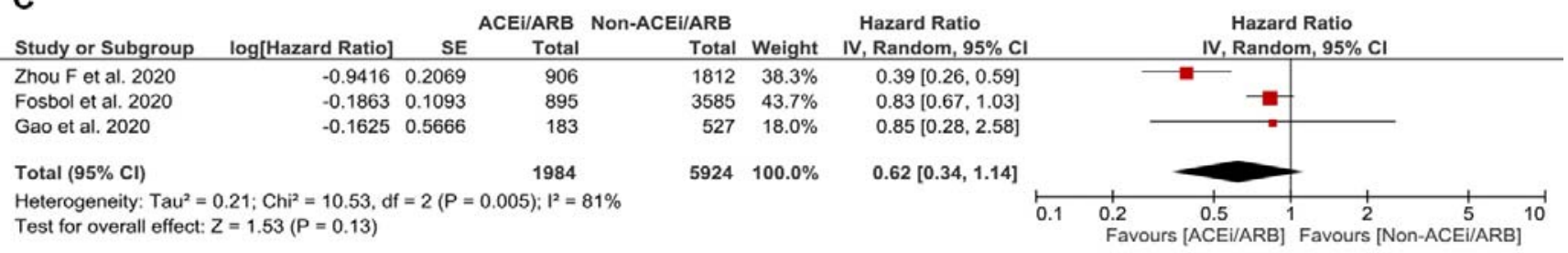

